\title{
Intracameral bevacizumab and mitomycin $C$ Trabeculectomy for eyes with neovascular glaucoma: a case series
}

\author{
Carlos Gustavo Vasconcelos de Moraes • \\ Antonio Carlos Facio Jr. • José Humberto Costa • \\ Roberto Freire Santiago Malta
}

Received: 14 July 2008 / Accepted: 10 March 2009/Published online: 31 March 2009

(C) The Author(s) 2009. This article is published with open access at Springerlink.com

\begin{abstract}
The purpose of this study was to describe the surgical outcomes and safety of intracameral bevacizumab during trabeculectomy in eyes with neovascular glaucoma. Pilot study included four eyes (four patients) with refractory neovascular glaucoma submitted to fornix-based trabeculectomy with adjunctive use of bevacizumab in the anterior chamber during the procedure. Patients were previously treated with panretinal photocoagulation as standard therapy. Variables evaluated were intraocular pressure, bleb appearance, iris neovascularization, intraoperative/postoperative complications, and visual outcomes. No intraoperative complication was observed. The mean follow-up period was 12.75 (range, 12-15 months). All eyes showed significant intraocular pressure control postoperatively. Iris neovascularization reduced significantly within 1 month after surgery. Mild anterior chamber inflammation was observed during follow-up in all eyes. No significant postoperative complication was observed, and no patient presented visual acuity deterioration. Intracameral bevacizumab may be used as an adjunctive therapy during trabeculectomy in eyes with neovascular glaucoma.
\end{abstract}

Keywords Neovascular glaucoma · Intraocular pressure · Bevacizumab · Trabeculectomy

C. G. V. de Moraes · A. C. Facio Jr. J. H. Costa • R. F. S. Malta Glaucoma Service, Department of Ophthalmology,

School of Medicine, University of Sao Paulo,

Sao Paulo, Sao Paulo, Brazil

C. G. V. de Moraes ( $\square)$

Glaucoma Service, The New York Eye and Ear Infirmary,

321 E 13th Street, 12G,

New York, NY 10003, USA

e-mail: gustavonyee@gmail.com

\section{Introduction}

Neovascular glaucoma (NVG) is an optic disc neuropathy caused by increased intraocular pressure (IOP), which results from secondary angle closure due to the growth of a neovascular membrane in the anterior chamber and trabecular meshwork [1,2]. Most cases of NVG are caused by ischemic retinal diseases, such as diabetic retinopathy and central or branch vein occlusions [2].

In such cases, standard treatment includes panretinal photocoagulation (PRP) in addition to anti-glaucomatous topical therapy [3-6]. Laser treatment aims to decrease the stimulus of retinal neovascularization, which is attributed to an increased concentration of vascular endothelial growth factor (VEGF) in retinal ischemic tissue [7-9]. Adjunctive therapy with topical medication delays the onset of glaucomatous optic neuropathy, and most of these patients will need glaucoma filtering procedures during follow-up $[1,10-15]$.

There is currently no prospective, randomized trial comparing success rates between trabeculectomy with antimetabolites and tube implantation in eyes with NVG. Non-comparative recent reports in the literature have shown similar success rates between the two procedures [12-15]. Yalvac et al. reported $63 \%$ success rate at 1 year using valved implants in eyes with NVG [15], whereas the success rates of trabeculectomy with antimetabolites ranged from $62 \%$ to $67 \%$ during the same follow-up time $[13,14]$. The Tube Versus Trabeculectomy Study Group excluded cases of iris neovascularization from their enrollment criteria. The investigators based on the consensus that the use of a glaucoma drainage implant (GDI) is the preferred surgical approach with these types of refractory glaucomas [16]. Nevertheless, most authors agree that GDIs are a 
better option in cases of NVG in a long-term follow-up [11, 15, 16]. Higher rates of failure following trabeculectomy could be caused by the growth of a neovascular membrane in the internal ostium of trabeculectomy, greater proximity of the iris to corneal endothelium, and increased anterior chamber inflammations in NVG eyes.

Bevacizumab (Avastin ${ }^{\circledR}$, Genentech, Inc., USA) is a monoclonal VEGF inhibitor that was first used in ophthalmology to treat subretinal neovascularization in eyes with age-related macular disease [17-19]. Recently, intravitreous injection of bevacizumab has been demonstrated to be a safe and successful alternative to treat retinal neovascularization in diabetic retinopathy and central or branch vein occlusions [20-25]. Previous studies reported that anterior chamber neovascularization may regress following intravitreous injection of bevacizumab in eyes with $\mathrm{NVG}$ [26-30], with [28, 29] or without [26, 30] adjunctive laser treatment. Similar results were observed following intracameral injections [31]. Since anterior chamber inflammation and neovascular membranes may cause increased risk of failure of filtration procedures, bevacizumab may be used as an adjunctive therapy during surgical treatment of NVG.

The aim of this study was to describe the surgical outcomes and safety of intracameral bevacizumab during trabeculectomy in eyes with NVG.

\section{Methods}

This is a pilot study including four NVG patients who underwent trabeculectomy with adjunctive use of bevacizumab in the anterior chamber during the procedure. Approval from the Institutional Review Board Ethics Committee was obtained for the study. The study followed the principles of the Declaration of Helsinki, and informed consent was obtained from all subjects.

All patients presented with anterior chamber neovascular membranes, closed angles during gonioscopy, and high IOP $(>21 \mathrm{mmHg})$. If the angle could not be seen due to corneal edema, we based our judgment on the depth of the peripheral anterior chamber (van Herick's test) and presence of iris neovascularization. PRP was performed at the time of the initial presentation. In order to avoid complications associated with excessive laser treatment in a single session, all eyes were treated within a minimum of three (range, three to five) consecutive visits, with a maximum of 300 shots each visit using a spot size of $250 \mu \mathrm{m}$ with delivery energy of 200-500 J. The aim was to allow a $360^{\circ}$ scatter PRP with a range of 900-1500 shots by the last visit. All eyes were on antiglaucoma medication by the time of the procedure.

Trabeculectomy was performed by two glaucoma specialists (ACFJ and JHC). Briefly, trabeculectomy was performed as follows: A fornix-based flap of conjunctiva and Tenon's capsule was created. After haemostasis of the episcleral blood vessels with wet-field cautery, a one-half thickness rectangular $(4.0 \times 2.0 \mathrm{~mm})$ scleral flap $(1.5 \mathrm{~mm}$ from the limbus) was outlined and dissected anteriorly without entry into the anterior chamber. Three surgical sponges measuring $2.0 \times 2.0 \mathrm{~mm}$ were soaked in a solution of $0.5 \mathrm{mg} / \mathrm{ml}$ mitomycin $\mathrm{C}$ (MMC). The sponges were placed over the dissected bed; a superficial scleral flap and the conjunctiva-tenon layer were then draped over the MMC-soaked sponges so that only those ocular tissues in contact with the sponges were directly exposed to MMC. After $3 \mathrm{~min}$, the sponges were removed, and MMC was irrigated thoroughly with $20 \mathrm{ml}$ balanced salt solution. A deep trabecular block was removed, and a peripheral iridectomy was performed.

The scleral flap was closed with three interrupted 10-0 nylon sutures. The conjuntivo-tenon flap was closed in the limbus using two interrupted 10-0 nylon sutures (one in each side of the flap, involving the corneal limbus-tenonconjunctiva). After the closure, the conjunctiva was shown to be watertight.

Then, $1.25 \mathrm{mg}$ of bevacizumab [32] $(0.05 \mathrm{ml}$ of $25 \mathrm{mg} / \mathrm{ml}$ solution) was injected in the anterior chamber through the

Table 1 Overview of surgical outcomes

\begin{tabular}{|c|c|c|c|c|c|c|c|}
\hline Patient & Diagnosis & $\begin{array}{l}\text { Preoperative } \\
\text { number of } \\
\text { medications }\end{array}$ & $\begin{array}{l}\text { Postoperative } \\
\text { number of } \\
\text { medications }\end{array}$ & $\begin{array}{l}\text { Preoperative } \\
\text { IOP }(\mathrm{mmHg})\end{array}$ & $\begin{array}{l}\text { Last visit } \\
\text { IOP } \\
(\mathrm{mmHg})\end{array}$ & $\begin{array}{l}\text { Follow-up } \\
\text { time } \\
\text { (months) }\end{array}$ & Complications \\
\hline 1 & PDR & 4 & 0 & 54 & 14 & 12 & - \\
\hline 2 & $\begin{array}{l}\text { PDR } \\
+\mathrm{BVO}\end{array}$ & 4 & 0 & 70 & 10 & 15 & $\begin{array}{l}\text { Flat anterior chamber, } \\
\text { serous choroidal } \\
\text { detachment }\end{array}$ \\
\hline 3 & PDR & 3 & 0 & 58 & 12 & 12 & - \\
\hline 4 & PDR & 4 & 0 & 44 & 10 & 12 & $\begin{array}{l}\text { Transient IOP elevation, } \\
\text { hyphema }\end{array}$ \\
\hline
\end{tabular}

$P D R$ proliferative diabetic retinopathy, $B V O$ branch vein occlusion 
access paracentesis. A drop of antibiotic-corticosteroid preparation and atropine $1 \%$ was instilled in the conjunctival sac, and a patch and shield were applied on the eye.

The postoperative medical regimen initially included $1.0 \%$ prednisolone eye drops administered every $2 \mathrm{~h}$ and then tapered over a period of 6 weeks, depending on the degree of inflammation. Atropine 1\% was dropped three times a day for the first 4 weeks after surgery. Topical antibiotic (moxyfloxacin, $0.5 \%$ ) was also administered four times daily during 2 weeks after surgery.

All patients were seen on the first postoperative day and then on the third, fifth, seventh, tenth, and 15 th day and then on the first, third, sixth, ninth, and 12th months thereafter. At each visit, complete ophthalmic evluation included best corrected visual acuity (BCVA), corneal appearance, anterior chamber depth, IOP measurements using Goldman tonometry, bleb appearance, and fundus examination.

\section{Results}

All patients presented with proliferative diabetic retinopathy, and one patient had a superimposed branch vein occlusion. None of the surgeries presented any intraoperative complication. The summary of each case is presented below (overview in Table 1).

\section{Patient 1}

A 65-year-old white woman with history of diabetic retinopathy presented with proliferative disease in the left eye. Preoperative IOP was $54 \mathrm{mmHg}$ using beta-blocker, alpha-agonist, and dorzolamide eye drops and oral acetazolamide $250 \mathrm{mg}$ four times daily. Peripheral anterior

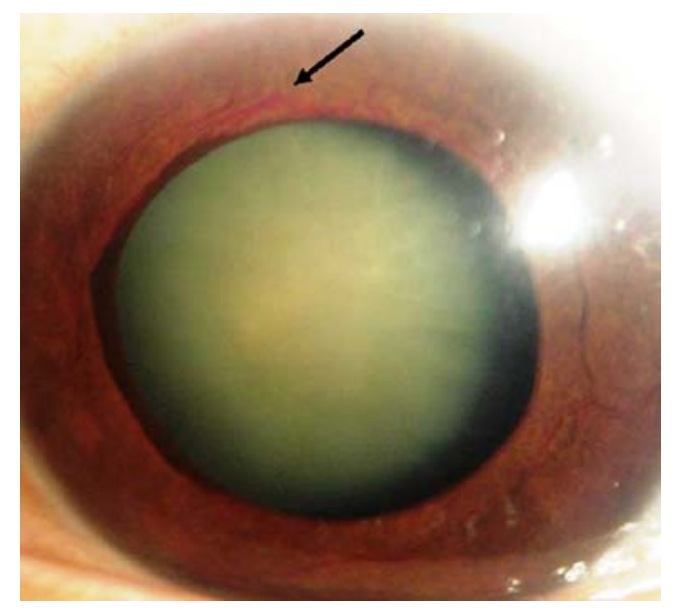

Fig. 1 Preoperative biomicroscopic examination. Note the extensive iris neovascularization, corneal edema, and mydriais (black arrow)

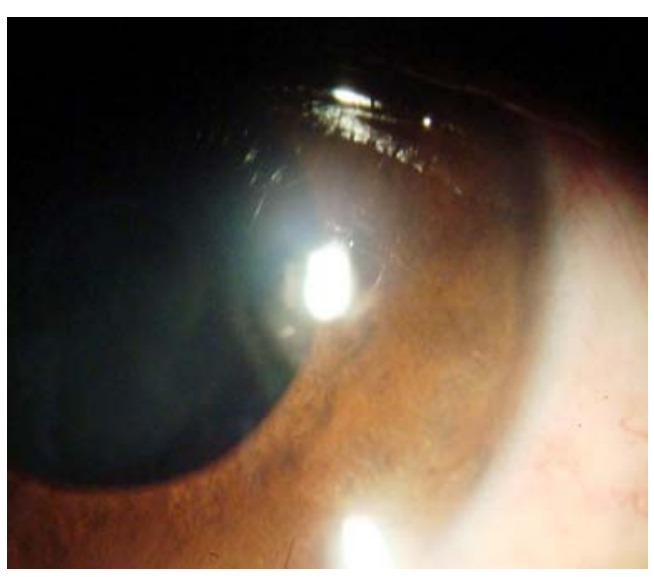

Fig. 2 First day post-surgery. Note the significant reduction of iris neovascularization

synechiae (PAS) were present in $180^{\circ}$ extension of the angle. BCVA was count fingers at $2 \mathrm{~m}$ (Fig. 1).

On the first postoperative day, the IOP was $12 \mathrm{mmHg}$ (initial reduction, 77\%), with a diffuse elevated bleb, mild corneal edema, and little anterior chamber reaction (Fig. 2). No change in fundus appearance was observed during indirect ophthalmoscopy.

By the end of the first week, the IOP was $10 \mathrm{mmHg}$. Suture lysis (one suture) was performed using argon laser on the 15th day visit due to transient mild IOP elevation. At the last follow-up visit (12 months), she presented with a visual acuity of $20 / 200$, likely due to decreased corneal edema, and the IOP was $14 \mathrm{mmHg}$ (final IOP reduction, $74 \%$ ). There was no sign of iris neovascularization by the last visit. The bleb conjunctiva looked more avascular than preoperatively and also less hyperemic than the surrounding non-operated conjunctiva.

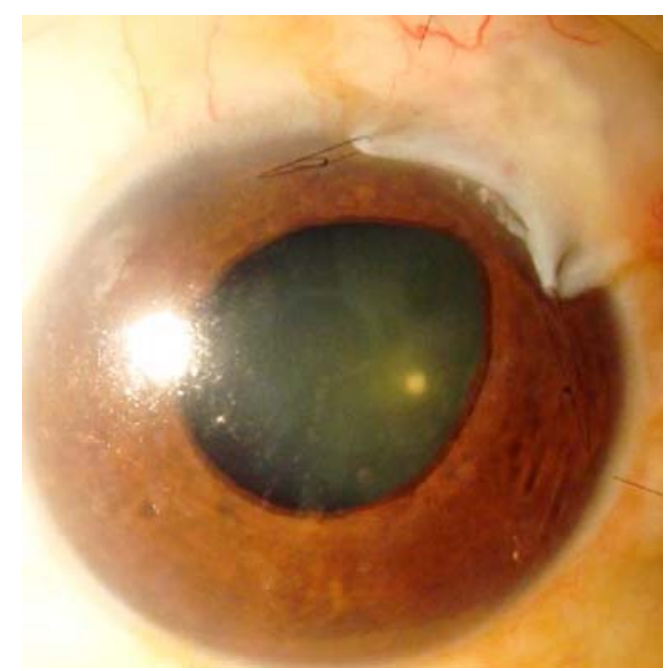

Fig. 3 One week after surgery. The bleb is diffuse, conjuctival vessels have small caliber, and anterior chamber inflammation is mild 


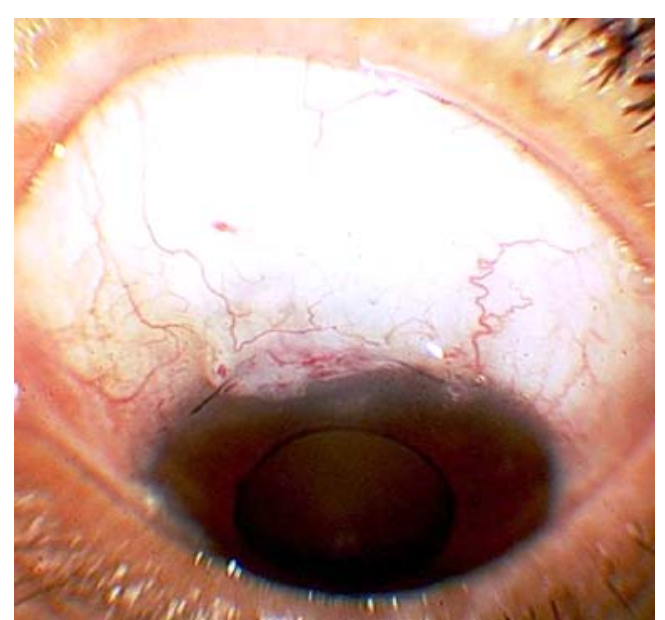

Fig. 4 One month after surgery. Note that the bleb is diffuse and avascular

\section{Patient 2}

A 37-year-old black man with previous diagnosis of diabetic retinopathy presented with branch vein occlusion in the right eye. Preoperative IOP was $70 \mathrm{mmHg}$ on maximal tolerated therapy. BCVA was hand-motion. The angle was closed in all four sectors during gonioscopy.

In the first postoperative day, the IOP was $14 \mathrm{mmHg}$ (initial reduction, $80 \%$ ). On the fifth day, he presented with flat anterior chamber (iridocorneal contact), with spontaneous resolution on the seventh day. An elevated non-vascular bleb was observed during all further follow-up visits. Fifteen months later, the IOP was $10 \mathrm{mmHg}$, and the BCVA was count fingers at $1 \mathrm{~m}$ (final IOP reduction, 86\%). There was significant decrease in iris neovascularization, and the bleb showed little hyperemia.

\section{Patient 3}

A 56-year-old white woman was diagnosed with proliferative diabetic retinopathy in the right eye. Preoperative IOP was $58 \mathrm{mmHg}$ on three antiglaucoma medications (beta blocker, alpha-agonist, and oral acetazolamide $250 \mathrm{mg}$ four times daily). BCVA was 20/80 preoperatively. The four sectors of the angle were closed during gonioscopy.

The intraocular pressure (IOP) was $10 \mathrm{mmHg}$ on the first postoperative day (initial reduction, 83\%). By the end of the first week, the IOP was $12 \mathrm{mmHg}$, and no sign of iris neovascularization was present (Fig. 3). By the last followup visit (12 months), the IOP was $12 \mathrm{mmHg}$ (final IOP reduction, $80 \%$ ) and visual acuity remained $20 / 80$. The iris and bleb remained avascular until the final visit.

\section{Patient 4}

A 45-year-old white woman presented with proliferative diabetic retinopathy, and the IOP was $44 \mathrm{mmHg}$ on maximal tolerated medication. BCVA was count-fingers at $2 \mathrm{~m}$, and anterior segment biomichoscopy showed intense iris neovascularization with flat anterior chamber. On the first postoperative day, the IOP was $8 \mathrm{mmHg}$ (initial reduction, $82 \%$ ) and showed continuous elevation until the 30th day visit when it reached $20 \mathrm{mmHg}$. Suture lysis was performed associated with subconjunctival injection of $0.5 \mathrm{mg}$ of 5 -fluorouracil. One month later, the IOP was $10 \mathrm{mmHg}$ and remained the same until the last visit (12 months; final IOP reduction, 77\%). BCVA improved to 20/100. Iris neovascularization was not evident during biomicrospic evaluation, and the bleb was avascular and less hyperemic than the surrounding conjunctiva (Fig. 4).
Fig. 5 Intraocular pressure profile following trabeculectomy with bevacizumab

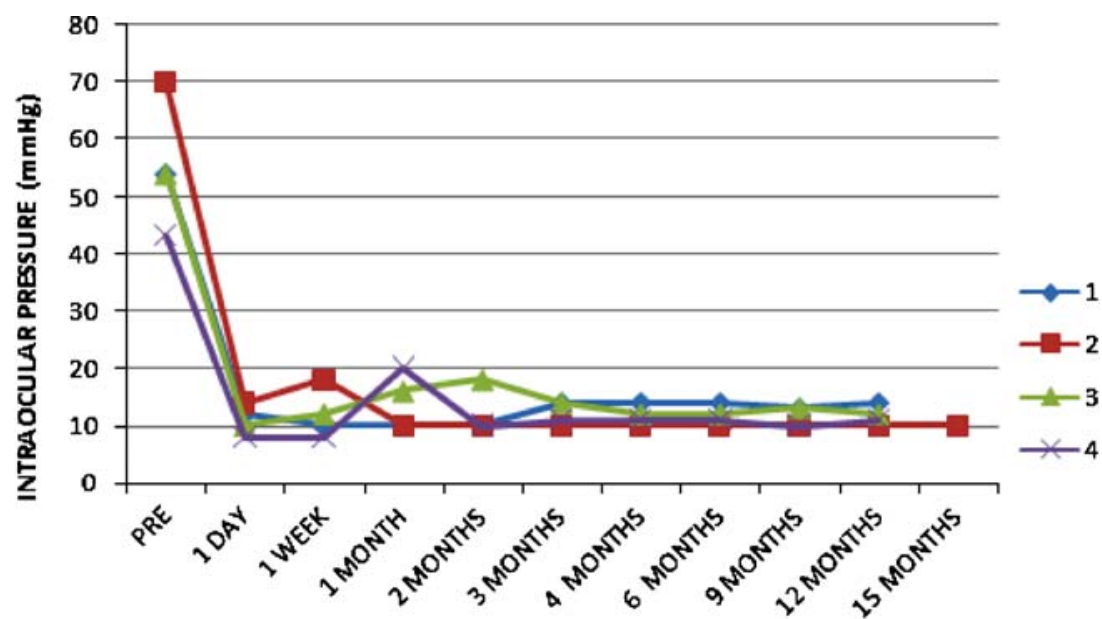

FOLLOW-UP TIME 


\section{Considerations/complications}

Biomicroscopic examination revealed complete regression of iris rubeosis by the last follow-up visit in all patients. Subjective evaluation of conjunctival vessels showed an improvement of ocular surface hyperemia following the procedure. Anterior chamber inflammation was considered mild (aqueous humor flare during slit-lamp examination) in all eyes within 1 week follow-up. By the second week after surgery, none of the operated eyes showed any subjective signs of anterior segment inflammation as determined by biomicroscopic evaluation. Patient 4 presented with hyphema $(2 \mathrm{~mm})$ during the first week, with further spontaneous resolution by the end of the second week. Mild serous choroidal detachment was seen in patient 3 with no further clinical consequences and resolved spontaneously (Fig. 5).

\section{Discussion}

In this study, a selected group of patients presented significant IOP reduction following trabeculectomy with adjunctive use of intracameral bevacizumab after an average follow-up period of 12.75 months. No significant intraoperative or late onset complication was reported.

Secondary glaucomas and eyes with previous intraocular surgery are at increased risk of failure following glaucomatous filtering procedures [33-35]. NVG may affect the properties of the conjunctiva and anterior chamber, resulting in increased risk of failure in eyes submitted to trabeculectomy. Glaucoma drainage implants are thus indicated as a further procedure in patients who did not present satisfactory IOP control with topical medication. Yet, GDIs are more expensive than standard trabeculectomy and may result in increased risk of short- and long-term complications (e.g., extrusion, diplopia, and endophthalmitis) [11]. Eyes with NVG were excluded from the Tube Versus Trabeculectomy Study, which may not allow us to make any definite assumptions whether GDIs represent an increased risk of future complications in NVG eyes [16]. Alternatively, adjunctive use of bevacizumab during trabeculectomy could be a safe and efficient procedure in NVG, as suggested in our study.

Intravitreal injection of bevacizumab has already been studied in NVG [28-30]. Geith and colleagues described a case series of six NVG patients who underwent PRP followed by intravitreal injection of bevacizumab [28]. The authors reported that eyes without synechiae showed satisfactory IOP control with topical eye drops alone, while those with PAS at the time of presentation needed subsequent glaucoma surgery. They suggested that intravitreal bevacizumab may be a valuable addition in the treatment of NVG by hastening the resolution of anterior segment neovascularization, improving the results of glaucoma surgeries, and appearing to give long-term control when used in combination with PRP. The procedure did not result in any relevant side effects in their study and showed a significant IOP decrease with mild inflammation.

Kahook et al. have reported a case of bleb needling revision using bevacizumab, demonstrating that the bleb was noted to be more diffuse with a decrease in surface neovascularization [36]. They suggested that the drug may be an effective medication for rescuing failing filtering blebs that exhibit neovascularization. In our study, it was noted that the number and caliber of vessels over the bleb significantly decreased after the surgery, unlikely what would be expected in cases of NVG. We believe that after the injection of bevacizumab, part of the drug diffuses through the sub-Tenon space resulting in decreased stimulus for neovascularization and bleb failure. A longer period of follow-up time is necessary to confirm this hypothesis. Iliev et al. evaluated glaucoma control in eyes with NVG following retinal vein occlusion after intravitreal injection of bevacizumab.[37] The authors observed rapid regression of iris and angle neovascularization and suggested further studies using VEGF inhibitors as adjunct therapy in the management of NVG. Recent reports described similar results and suggested new perspectives in the treatment of this type of refractory glaucoma [38, 39]. Our study confirmed those findings and also addressed one of its potential uses in glaucoma management.

One limitation of our study was the lack of a control group. Nevertheless, trabeculectomy with antimetabolites and bevacizumab should be compared with a control group without bevacizumab. However, since it is well known that trabeculectomy (even with adjunctive MMC) has high risk of failure in NVG, a comparative study using a group without bevacizumab would face ethical issues. Alternatively, a comparative study with tube implants would be biased for using a completely different surgical modality. Due to the lack of a control group, we cannot speculate whether the observed results are due to the intracameral use of bevacizumab or the PRP combined with the use of MMC intraoperatively. Based on our experience and on the available literature, the success rates of trabeculectomy even with adjunctive use of antimetabolites are very low (approximately 58\% in 2 years) [13]. It is possible that the transitory anti-VEGF effect of the drug might have contributed to success by reducing inflammation and inhibiting excessive bleb vascularization, which are the main causes of failure in these eyes. Despite the growing use of monoclonal VEGF inhibitors in retinal disease, it is consensus that PRP should always be considered as first choice treatment in neovascular retinal diseases, as it has been validated by the major clinical trials in the area $[3,4]$. 
We also used a high concentration of MMC $(0.5 \mathrm{mg} / \mathrm{ml})$ in these eyes, which may have also contributed to the avascular appearance of the bleb during follow-up.

In summary, intracameral injection of bevacizumab during trabeculectomy in this sample of patients with NVG resulted in satisfactory IOP control during a mid-term follow-up period with minor complications. Further prospective casecontrol studies are necessary to confirm these results.

Financial disclosure The authors have no financial interest in this article

Open Access This article is distributed under the terms of the Creative Commons Attribution Noncommercial License which permits any noncommercial use, distribution, and reproduction in any medium, provided the original author(s) and source are credited.

\section{References}

1. Sivack-Callcott JA, O’Day DM, Gass DM, et al. Evidence based recommendations for the diagnosis and treatment of neovascular glaucoma. Ophthalmology. 2001;108:1767-76.

2. Allingham RA, Damji KF, Freedman S, et al. Glaucomas associated with disorders of the retina, vitreous and choroids. In: Shields' Textbook of Glaucoma, 5th edn. Philadelphia: Lippincott, Williams \& Wilkins; 2005.

3. Central Vein Occlusion Study Group. Natural history and clinical management of central retinal vein occlusion. Arch Ophthalmol. 1997;115:486-91.

4. Aylward GW, Pearson RV, Jagger JD, Hamilton AM. Extensive argon laser photocoagulation in the treatment of proliferative diabetic retinopathy. Br J Ophthalmol. 1989;73:197-201.

5. Doft BH, Blankenship GW. Single vs multiple treatment sessions of argon laser panretinal photocoagulation for proliferative diabetic retinopathy. Ophthalmology. 1982;89:772-9.

6. Kaufman SC, Ferris FLIII, Seigel DG, et al. Factors associated with visual outcome after photocoagulation for diabetic retinopathy: diabetic retinopathy study report 13 . Invest Ophthalmol Vis Sci. 1989;30:23-8.

7. Adamis AP, Miller JW, Bernal MT, et al. Increased vascular endothelial growth factor levels in the vitreous of eyes with proliferative diabetic retinopathy. Am J Ophthalmol. 1994; 118:445-50.

8. Aiello LP, Avery RL, Arrigg PG, et al. Vascular endothelial growth factor in ocular fluid of patients with diabetic retinopathy and other retinal disorders. N Engl J Med. 1994;331:14807.

9. Pe'er J, Shweiki D, Itin A, et al. Hypoxia-induced expression of vascular endothelial growth factor by retinal cells is a common factor in neovascularizing ocular diseases. Lab Invest. 1995;72:638-45.

10. Sidoti PA, Dunphy TR, Baerveldt G, et al. Experience with the Baerveldt glaucoma implant in treating neovascular glaucoma. Ophthalmology. 1995;102:1107-18.

11. Hong CH, Arosemena A, Zurakowski D, et al. Glaucoma drainage devices: a systematic literature review and current controversies. Surv Ophthalmol. 2005;50:48-60.

12. Sivak-Callcott JA, O'Day DM, Gass JD, et al. Evidence-based recommendations for the diagnosis and treatment of neovascular glaucoma. Ophthalmology. 2001;108:1767-76.
13. Takihara Y, Inatani M, Fukushima M, et al. Trabeculectomy with mitomycin $\mathrm{C}$ for neovascular glaucoma: prognostic factors for surgical failure. Am J Ophthalmol. 2009, (in press).

14. Kiuchi Y, Sugimoto R, Nakae K, et al. Trabeculectomy with mitomycin $\mathrm{C}$ for treatment of neovascular glaucoma in diabetic patients. Ophthalmologica. 2006;220:383-8.

15. Yalvac IS, Eksioglu U, Satana B, et al. Long-term results of Ahmed glaucoma valve and Molteno implant in neovascular glaucoma. Eye. 2007;21:65-70.

16. Tube Versus Trabeculectomy Study Group. The tube versus trabeculectomy study: design and baseline characteristics of study patients. Am J Ophthalmol. 2005;140:275-87.

17. Avery RL, Pieramici DJ, Rabena MD, et al. Intravitreal bevacizumab (Avastin) for neovascular age-related macular degeneration. Ophthalmology. 2006;113:363-5.

18. Krzystolik MG, Afshari MA, Adamis AP, et al. Prevention of experimental choroidal neovascularization with intravitreal antivascular endothelial growth factor antibody fragment. Arch Ophthalmol. 2002;120:338-46.

19. Rosenfeld PJ, Moshfeghi AA, Puliafito CA. Optical coherence tomography findings after an intravitreal injection of bevacizumab (Avastin) for neovascular age-related macular degeneration. Ophthalmic Surg Lasers Imaging. 2005;36:331-5.

20. Arevalo JF, Wu L, Sanchez JG, et al. Intravitreal bevacizumab (Avastin) for proliferative diabetic retinopathy: 6-months followup. Eye. 2007;23:117-23.

21. Ishikawa K, Honda S, Tsukahara Y, et al. Preferable use of intravitreal bevacizumab as a pretreatment of vitrectomy for severe proliferative diabetic retinopathy. Eye. 2007;23:10811.

22. Lynch SS, Cheng CM. Bevacizumab for neovascular ocular diseases. Ann Pharmacother. 2007;41:614-25.

23. Costa RA, Jorge R, Calucci D, et al. Intravitreal bevacizumab (Avastin) for central and hemicentral retinal vein occlusions: IBeVO study. Retina. 2007;27:141-9.

24. Avery RL, Pearlman J, Pieramici DJ, et al. Intravitreal bevacizumab (Avastin) in the treatment of proliferative diabetic retinopathy. Ophthalmology. 2006;113:1695.

25. Jaissle GB, Ziemssen F, Petermeier K, Szurman P, Ladewig M, et al. Bevacizumab for treatment of macular edema secondary to retinal vein occlusion. Ophthalmologe. 2006;103:471-5.

26. Bock F, Konig Y, Dietrich T, et al. Inhibition of angiogenesis in the anterior chamber of the eye. Ophthalmologe. 2007;104:33644.

27. Kiss C, Michels S, Prager F, et al. Evaluation of anterior chamber inflammatory activity in eyes treated with intravitreal bevacizumab. Retina. 2006;26:877-81.

28. Gheith ME, Siam GA, De Barros DS, et al. Role of intravitreal bevacizumab in neovascular glaucoma. J Ocul Pharmacol Ther. 2007;23:487-91.

29. Chilov MN, Grigg JR, Playfair TJ. Bevacizumab (Avastin) for the treatment of neovascular glaucoma. Clin Exp Ophthalmol. 2007;35:494-6.

30. Batioglu F, Astam N, Ozmert E. Rapid improvement of retinal and iris neovascularization after a single intravitreal bevacizumab injection in a patient with central retinal vein occlusion and neovascular glaucoma. Int Ophthalmol. 2007;28:59-61.

31. Grisanti S, Biester S, Peters S, et al. Tuebingen Bevacizumab Study Group. Intracameral bevacizumab for iris rubeosis. Am J Ophthalmol. 2006;142:158-60.

32. Jonas JB, Spandau UH, Schlichtenbrede F. Intravitreal bevacizumab for filtering surgery. Ophthalmic Res. 2007;39:121-2.

33. Lavin MJ, Wormald RP, Migdal CS, et al. The influence of prior therapy on the success of trabeculectomy. Arch Ophthalmol. 1990;108:1543-8. 
34. Bayer AU, Erb C, Ferrari F, et al. The Tubingen Glaucoma Study. Glaucoma filtering surgery-a retrospective long-term follow-up of 254 eyes with glaucoma. Ger J Ophthalmol. 1995;4:289-93.

35. Jacobi PC, Dietlein TS, Krieglestein GK. Primary trabeculectomy in young adults: long-term clinical results and factors influencing the outcome. Ophthalmic Surg Lasers. 1999;30:63746.

36. Kahook MY, Schuman JS, Noecker RJ. Needle bleb revision of encapsulated filtering bleb with bevacizumab. Ophthalmic Surg Lasers Imaging. 2006;37:148-50.
37. Iliev ME, Domig D, Wolf-Schnurrbursch U, et al. Intravitreal bevacizumab (Avastin) in the treatment of neovascular glaucoma. Am J Ophthalmol. 2006;142:1054-6.

38. Miki A, Oshima Y, Otori Y, et al. Efficacy of intravitreal bevacizumab as adjunctive treatment with pars plana vitrectomy, endolaser photocoagulation, and trabeculectomy for neovascular glaucoma. Br J Ophthalmol. 2008;92:1431-3.

39. Wakabayashi T, Oshima $\mathrm{Y}$, Sakaguchi $\mathrm{H}$, et al. Intravitreal bevacizumab to treat iris neovascularization and neovascular glaucoma secondary to ischemic retinal diseases in 41 consecutive cases. Ophthalmology. 2008;115:1571-80. 